\title{
The communication aspect of specialists' professional competence
}

\author{
Lyudmila Znikina ${ }^{1, *}$, Natalia Mamontova ${ }^{1}$ and Pavel Strelnikov ${ }^{1}$ \\ ${ }^{1}$ Department of Foreign Languages, Kuzbass State Technical University, Kemerovo, Russia
}

\begin{abstract}
In the article the issues of specialists' professional competence in a multicultural context are considered from the perspective of information and communication concepts. It is proved that the main objective of communication process is the adequate interpretation of communicants' intentions. Communication competence of a specialist is seen as a resource to provide language and intercultural readiness for work, social flexibility and interaction on a professional level, including multicultural work environment, in the conditions of global academic mobility and expansion of business contacts.
\end{abstract}

\section{Introduction}

Modern society development, socio and economic realities of society integration into a universe economic and educational environment dictate the tough conditions for today's international labor market which requires professionals who are trained for functioning with multipurpose intercultural contacts. Developing communicative behavior strategy among partners in interpersonal and professional interaction, especially in the framework of intercultural communication, becomes the key aspect in the professional activity of multiambitious specialists. These are the specialists of a new level - the ones with high professional and socio-cultural competence, which provides them competitiveness in the international labor market, gives an opportunity to implement the society needs in the conditions of expanding economic environment and dynamic international cooperation. The politically correct ability of a communicator to convey the message to another person becomes really important.

In other words, one of the significant qualities is the ability to interact effectively with representatives of another culture including different stages of scientific and academic activities. They may include organizing domestic scientific conferences, participation in international scientific conferences, preparing documents for educational and scientific grants, learning how to use the terms and conditions of studying abroad, participating in business negotiations (as a member of a team of experts, a representative of a work department, a technical specialist of specialized aspects for contracts with enterprises from partner countries, etc.).

\footnotetext{
*Corresponding author: znikina@,kuzstu.ru
} 
Recently specialists have considered this issue not as a significant problem and would comment that 'professionals will find common ground independently of the cultural traditions they were brought-up in' [1]. But in recent time the importance and urgency of the problem of intercultural interactions is appreciated by a wider audience of politicians, entrepreneurs and all those who have to work with people from other cultures. On the contrary, unfamiliarity and sometimes unacceptable communication styles adopted in the host country due to cultural traditions significantly complicate the adaptation of foreigners to the culture and prevent the fruitful cooperation establishment.

\section{The results and discussion}

One of the requirements to the level of professional competence development of a specialist is simply the ability to communicate. 'Unfortunately, many of them have some patterns of thinking; they do not have enough knowledge of the world, patience and perseverance to negotiate with people of other cultures and other ways of thinking. They are just not international' [2].

One of the possibilities for internationalizing business relations is learning foreign languages. But in order to prepare professionals for effective intercultural contacts, knowledge of a foreign language must be supplemented by knowledge of the nature of intercultural interaction with all the features of verbal and non-verbal aspects. It's the time when it's possible to talk about the ability to integrate intercultural knowledge and intercultural communication experience in the course of professional activities. The abilities of modern specialist for intercultural communication may generally include:

- perceiving and interpreting different cultural values;

- considering the various cultural phenomena and other cultures representatives from the standpoint of empathy;

- being able to review and change their assessment of a 'foreign' culture in the process of improving skills and gaining experience in intercultural communication;

- changing self-evaluation of one's behaviour while comprehending a "foreign" culture;

- generalizing one's personal experience while participating in an intercultural dialogue.

Communication business differences are based on the conceptual difference in the approaches to both intercultural and linguistic interaction. The sequence of possible problem situations in intercultural communication can be summarized as follows: lack of basic intercultural knowledge $\rightarrow$ unawareness of communication peculiarities of other cultures representatives $\rightarrow$ the communication gap or culture bump $\rightarrow$ the inability to achieve the communicative purpose $\rightarrow$ stress $\rightarrow$ generalization and categorization of the problem $\rightarrow$ biased perception of communication (as well as language) situation $\rightarrow$ refusal of potential direct contacts.

The concept of 'intercultural communication' (in other terms - cross-cultural communication, multicultural communication) does not currently have a precise definition. One thing is clear - it is a synthesis of 'culture' and 'communication' concepts. This may define intercultural communication as interpersonal interaction between members of different groups, who have different views on the level of knowledge inherent to these groups, and different language characters.

Speaking of differences, we cannot avoid mentioning the fact that the ambiguous attitude to other cultures existed throughout the human history. In a modified form, the dilemma persists in modern conditions and is leading to the debates and discussions of specialists on the content, object, subject and purpose of intercultural communication. This has resulted in several theories of intercultural communication, which consider various aspects of interactions of cultures. The most well-known theories of intercultural communication include the theory of the American anthropologist Edward T. Hall, the 
theory of cultural dimensions by the Dutch socio-psychologist and anthropologist Geert Hofstede, the theory of cultural literacy by the American educator E. Hirsch.

Anthropologist Edward T. Hall wrote extensively about context, he highlighted not only the cultural and communicative models of different groups [2], but developed a common typology in relation to their context [3]. According to his theory context is information surrounding and accompanying a particular cultural event. Cultures differ in their interpreting the context. Although he categorizes cultures as being either high-context or low-context, context really is a cultural dimension that ranges from high to low. In highcontext cultures most of the information is either in the physical context or is internalized in the people who are a part of the interaction. Very little information is actually coded in the verbal message. In low-context cultures, however, most of the information is contained in the context or within the participants. In other words, low-context cultures are those in which social context surrounding a negotiation counts as nothing; all that counts are the actual written agreements. Those societies in which the social context that surrounds a formal, written document is far more important than the written, legal documentation are called high-context cultures. Hall also differentiated between monochromic or polychromic aspects of cultural differences.

In the theory of cultural dimensions, Geert Hofstede proves [4] that each person perceives the world in a special way under the influence of individual peculiarities of the psyche, social environment and specific features of an ethnic culture. The vast majority of social behaviour is formed in childhood, because it is in childhood when a person is most sensitive to learning processes. The result of a process of forming feelings, thoughts and behaviour are the so-called mental programs that can be explored using dimensions of culture according to the four indicators. Hofstede emphasises the predominance of certain traits in the national character:

- power distance - comparison of cultures according to the degree of concentration of power or its distribution on various levels of the organization;

- collectivism / individualism - encouragement of social communication as opposed to individual independence and reliance on one's own strength;

- masculinity / femininity - a clear delineation of gender roles;

- uncertainty avoidance - comparison of cultures according to the degree of acceptable deviations from established norms and values.

Although the Hofstede's theory has some kind of a restricted character, the given parameters of cultural differences allow to respond flexibly to unexpected actions of partners in intercultural communication and to avoid possible conflicts when dealing with other cultures.

The theory of cultural literacy by E.D. Hirsch, Jr. is based on the fact that a necessary condition for effective intercultural communication is an adequate level of cultural literacy, which involves understanding the background knowledge, values, psychological and social identity which are typical of a particular culture. For a successful language competence, deep knowledge of the various cultural symbols of the respective national culture is required. E. Hirsch in his theory believes that cultural literacy 'makes us masters of the standard instrument of knowledge and communication, thus allowing us to send and receive complex information orally and in writing, in time and space' [5]. Depending on the value and role of a particular type of communication in specific situations Hirsch distinguishes different levels of intercultural competence: the level required for 'survival'; the level sufficient for entry into a foreign culture; the level that ensures a real-life existence in a new culture - its 'appropriation'; the level, allowing to realize fully the identity of a language user.

An important feature of intercultural communication is that one of the partners involved in it has to use the second (foreign) language, which is not any version of their own. In 
general, (Fig. 1) the process of intercultural communication can be represented in the form of a communication model developed by Gudykunst and Kim [7].

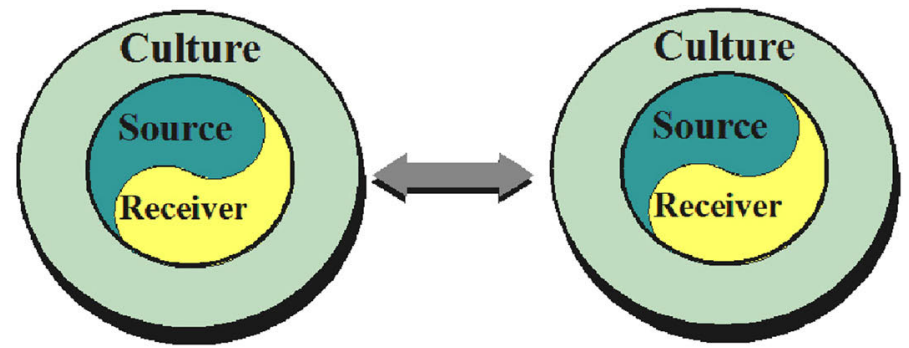

Fig. 1. Model of intercultural communication

Both communication partners are influenced by their perceiver filters on the basis of which they select and divide into categories the environment and information. The authors define this filter as a mechanism which helps us 'encode and decode a message' [7]. This global impact is due to the macro-system of the culture. It is also necessary to consider the impact of the middle level, which is the result of social relations and mental system of the individual. Each of these filters affects both the processes of encoding and decoding of the parties who fulfil simultaneously the roles either of the communicator or the recipient in the interactive process due to the circumstances. To convey a message to the recipient, the communicator must encode it specifically. There are many possible codes but verbal and non-verbal codes are of special interest here. The encoding processes, the act of the message interpretation obviously depend on the appropriate filters. Information transfer occurs when the conceptual filters of the parties are relatively similar (semantically tuned).

This model can serve as an example to identify characteristics and potential problems of intercultural communication in a professional context. Issues of intercultural communication and intercultural differences should be logically considered through the way of thinking and norms of behaviour of representatives of a particular culture that in fact may hinder communication. In communication, we behave subconsciously in accordance with social and communicative norms of our native culture: socio-historical background determines our values, behaviour and customs. That is why any message can be interpreted in different ways in a particular social or professional context in intercultural communication. As mentioned above verbal or nonverbal behaviour together with the lack of knowledge of the peculiarities of intercultural and communicative environment can lead to the wrong conclusions about the personal and professional qualities of a person in the communication process. According to the information theory, communication is the means of conveying information. Therefore, we consider it appropriate to refer to the relationship between the concepts 'information' and 'communication'.

If we analyse the frequency of use of certain concepts in scientific research or even in everyday life, then, undoubtedly, information tops the list and comprises everything that bears the traces of knowledge, messages, data, signals, etc. Information interactions are the basis of the existence of both the living and inanimate natures. Without information processes, social life is also unthinkable.

In scientific literature one can find dozens of definitions of information. However, it is impossible to give a complete definition to the concept of information since the term "information" has been widely used not only in scientific literature but also in other areas of our lives. So, information is commonly understood in the broadest sense as all knowledge, data, facts, messages, signals, which we deal with in everyday life and the manifestation of which we observe in nature and society. 
Let's note, however, that the term 'information' comes from the Latin word 'informatio', which can be interpreted as the message, explanation, description. Moreover, we take the liberty to say that such interpretation of information is conceptually very close to the concepts of education, training. Thus, in the process of comprehension it is information that makes us 'correct' and 'upgrade' our knowledge. That is why the value of information is always subjective and is largely determined by the capabilities of information consumers, their purposes, also by the degree of their sensitivity and the level of their knowledge.

It's worth considering how the concepts of 'information', 'communication' and 'message' correlate and the latter concept is one of the most common forms of representation of information. In his fundamental work 'Informatics' F. L. Bauer introduces the concepts of 'communication' and 'information' as the basic concepts, meaning that all other informatics concepts are derived from them [8].

To define the message using the concept of information is not difficult: for example, a message is a set of signs or primary signal containing information. It is important to emphasize that the message in the communication process has completely different information for each category of people that suits the interests of the recipient.

Thus, the same message in the communication process (verbal or non-verbal) can be interpreted in different ways and carry different types of information: incoming and outcoming ones may be different. Meanwhile it can be argued that some kind of image which is either the result of an agreement or awareness, or is prescribed by the rule is decisive for the connection between the message and the information contained in it. This image is a rule of interpretation. The interpretation itself is determined by the interests of information recipients, their feelings, emotions and, speaking more formal language, just by their purpose. In this case, it is easy to imagine that one of the main conditions to extract the necessary information from the message is actually the purpose of this process.

In the context of our study the idea of communication as means of target sending and receiving information in the form of knowledge, data, facts, messages and signals coincides with the model of intercultural communication shown in Fig. 1. Thus we characterize communication as a phenomenon, supporting the processes of understanding, accumulation and systematization of knowledge, decision-making processes and management. Let's call this function of communication instrumental-functional.

Such communication rules in specific contexts are based on the system of expected behaviour patterns, which foster verbal forms of interaction among individuals. But it is decision making that precedes people's activities. This kind of decision making can be a carefully thought-out, conscious act which is based on a logical analysis. But it can also be based on some intuitive ideas and emotions, made on a whim. Moreover, the decision may be taken in a state of stresses and strains. In any case, the act of making decisions is a discharge of socio-psychological energy, which normally occurs as a result of communication in the form of information and signal effects. At the same time, communication is a tool of influence, causing the discharge of socio-psychological energy, which leads to making decisions and taking specific actions. Communication as a tool of signal impact can be schematically presented as follows: information $\rightarrow$ acc umulation $\rightarrow$ signal impact $\rightarrow$ energy discharge (actions, comprehension, decision making). Many factors are the reasons for such psychological reactions. Principal among them is the lack of awareness about the realities and negotiating style of a partner country; low language competence can be mentioned second.

Thus, communication performs on the one hand 'ensuring' function representing the method of transferring information, knowledge, content of messages that are interpreted on the basis of goals and objectives. On the other hand, communication can perform directly influencing function forming the basis for those signals which can stimulate the accumulation of energy, its transformation and, finally, discharge, transforming the system 
into a 'new' condition, and in some cases simply destroying it. This coincides perfectly with the previously presented chain of causes and sequences of possible problem situations in intercultural communication.

It is clear that for successful communication knowledge of linguistic code alone is not enough: in addition, one should know the fundamentals and characteristics of communication in native and foreign cultures. Moreover, the study of communication is interdisciplinary, since it requires joint efforts of representatives of different professions: sociologists, linguists, culturologists, psychologists, and teachers.

Dealing with the problems of communication has become particularly urgent in the business environment. In the business world, the significance of cultural differences and the role of intercultural communicator have been under discussion. 'These days there is not a discussion or a decision that does not have an international dimension. We would have to be blind not to see how critically important international experience is' [9]. As companies integrate their operations globally different national approaches can send conflicting messages to success-oriented communicators.

Meanwhile intercultural characteristics can become a barrier which may hinder communication and prevent communicators from realizing their communicative intentions. The challenges of business communication generally include developing negotiation and motivation strategies and tactics to avoid communication breakdowns [10]. It is necessary to take into consideration national leadership styles and avoid national stereotypes that can ruin communication. It is a well-known fact that technical knowledge and skills make up only $15 \%$ of business success while $85 \%$ depends on the ability to communicate with other people. One can only imagine how much money businesses lose, and how many promising business ideas will never be implemented due to the fact that basic rules of communication are not observed.

English consultants in management psychology Mike Woodcock and Dave Francis noted that managers need, above all, the ability to manage themselves and influence others through the ability to communicate. The list of requirements can be added with the following: 'Ideally, it seems a global manager should have the stamina of an Olympic runner, the mental ability of an Einstein, the conversational skill of a professor of languages, the detachment of a judge, the tact of a diplomat, and the perseverance of an Egyptian pyramid builder. And that's not all. If they are going to measure up to the demands of living and working in a foreign country, they should also have a feeling for the culture; their moral judgment should not be too rigid; they should be able to merge with the local environment; and they should show no signs of prejudice' [11].

There is perhaps one main conclusion to be drawn from the above discussion concerning specialists' training: fundamental professional knowledge must be backed up by the knowledge of communication as a management tool. In our case we find it appropriate to present some findings $[1,12]$.

- Communication in a business context is initially focused on and directed to the target.

- Managers communicate not only with each other, but with representatives of external communities.

- In a business context there is no free choice of the communicative partners, there is a 'compulsive communication'.

- Communication is a prerequisite for functioning of the system 'Business'.

The following preliminary conclusion would be logical: the aspect of training a competitive specialist is reasonably important. The purpose of business communication training is to acquire competences of two-way communication necessary for identifying common interests and mutual understanding based on knowledge of communication rules and cultural awareness. 


\section{Conclusion}

The demands of modern society and the priorities of socio-economic development of a society determine the level and content of competences required for specialists' professional training. The analysis of the socio-economic realities revealed a number of contradictions typical of the modern education system: first, between the need for education of the individual and public expectations; between the need for highly qualified specialists of a new level and training practices of these professionals in accordance with their further professional orientation. There is formation not only of knowledge and skills, but also the development of skills and social competences of a personality required to implement that knowledge. Intercultural communication is regarded as an important component of the overall professional competence of the specialist in the field of management. In the modern educational paradigm, values such as social capital, intercultural communication, tolerance and respect for cultural differences, knowledge of a foreign language have become important.

\section{References}

1. B. Lentz, Manager Magazin, 5, 257 (1997)

2. E. Hall. Psychology Today, 6, 67 (1976)

3. E. Hall, The dance of life (New York, 1983).

4. G. Hofstede, Cultures and Organisations. Software of the Mind (London, 1993)

5. E. Hirsh, Cultural Literacy (What Every American Needs to Know) (Boston, 1988)

6. K. Knapp, Zeitschrift für Fremdsprachenforschung, 1, 66 (1990)

7. W. Gudykunst, Y. Kim, Communicating with Strangers (New York, 1992)

8. F. Baujer, G. Gooz, Informatika (Mir, 1990).

9. N. Adler, International Dimentions of Organisational Behaviour (South-Western College Publishing Ohio, 1997).

10. P. O'Connor, A. Pilbeam, F. Scott-Barrett, Negotiating (Longman Group UK Limited. 1996)

11. M. Woodcock, D. Fransis, The unblocked manager. A practical guide to self development (1991)

12. A. Pilbeam, Market Leader. International Management (Longman: Pearson Education Limited, 2003) 